Indexaciones: Repositorio de Revistas UCR, DIALNET, Latindex, REDALYC Directorio y recolector de recursos digitales del Ministerio de Cultura de España, Directory of Open Access Journals. Diálogos Revista Electrónica de Historia ISSN 1409-469X. Número especial 2008. Dirección web: http://historia.fcs.ucr.ac.cr/dialogos.htm

\title{
"La verdadera felicidad de las indias". Trabajo forzado en la Real Fábrica de Pólvora (1774-1776)
}

\author{
Beatriz Palomo de Lewin, Historiadora
}

Dirección Postal: Km.13 Carretera a El Salvador Los altos \# 23 Santa Catarina Pinula.

Guatemala, Centro América

TEL. 66341123

Correo electrónico: bpalomo@uvg.edu.gt y

beatrizlewin@hotmail.com

Filiación Institucional: Universidad del Valle de

Guatemala. 


\section{"La verdadera felicidad de las indias": \\ Trabajo forzado en la Real Fábrica de Pólvora (1774-1776)}

\section{Beatriz palomo de Lewin}

\section{Universidad del Valle de Guatemala}

\section{Introducción}

Cuando filósofos y filosofas, historiadores e historiadoras hablan del trabajo, lo hacen siguiendo una tradición idiomática "el trabajo del hombre", como una categoría universal, que no contempla la especifidad de las mujeres, convirtiendo el trabajo femenino en un tema marginal y marginado, por la corriente principal de investigación.

El objeto de este trabajo es rescatar un retazo de la historia de las mujeres en Guatemala, y poner en tela de juicio el paradigma "los hombres trabajan, la mujeres cuidan de los hijos y del hogar" establecido por la sociedad patriarcal, en la historia de Guatemala.

Esta tarea se enfrenta con varias dificultades "porque las mujeres han sido, sobre todo las trabajadoras, los personajes segundos de la historia y, al no ostentar poder, han dejado pocas huellas de sus penas. Tanto más cuanto a menudo carecían más cruelmente de la instrucción que los hombres, y los cronistas hubiesen creído perder el tiempo al hablar de la manera con

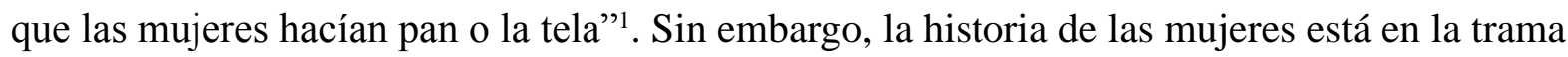
de la vida y para explicar el tejido social tenemos que deshilar y allí mismo, corremos el riesgo de tornar irreconocible el tejido que tratamos de explicar: los imaginarios colectivos, entrelazados con la lucha de poder entre la Corona y la Iglesia, la estructura social donde 
relucen los diferentes colores de los grupos étnicos que la constituyen (españoles, indígenas y africanos), nuevamente entrelazado con el estatus de las mujeres, las mujeres indígenas y en especial las viudas, todo esto anudado a los mecanismos de supervivencia que utilizan los oprimidos, y aún así distinguimos el hilo del miedo a la indiferenciación, en una sociedad construida sobre la diferencia, que legitima el estatus.

El englobar el trabajo de hombres y mujeres en la categoría del "trabajo del hombre" ha sido señalado como un mecanismo de invisibilización de las mujeres. El rasgo universalista de los historiadores, y aún historiadoras, contribuye a que los documentos que contienen información directa sobre las mujeres, sean incluidos, pero en cierta manera, pasados por alto, en lo que concierne a la vida de las mujeres. Es precisamente por está razón que he tenido la oportunidad de analizar un documento encontrado por René Johnston en su trabajo “La real fábrica de Pólvora en Santiago de Guatemala"2, sin cuya ayuda hubiera sido imposible esta investigación, que también se apoya en otros documentos de archivo, bibliografía y trabajos anteriores realizados por la que escribe.

En seguida presento la historia reconstruida de la denuncia presentada por el presbítero Pineda ante las autoridades reales.

Un lunes de 1797, muy de madrugada, la plaza del pueblo de Jocotenango se encuentra vacía, poco a poco, a tiempo que los primeros rayos de sol se vislumbran, van llegando al lugar, mujeres del pueblo, que han sido asignadas por el gobernador para ir y trabajar a la fábrica de pólvora. Tienen que darse prisa porque la entrada es a las 6:00 de la mañana y hay que caminar el sendero que las lleve a "El Cabrejo", lugar donde se encuentra el trabajo, en las 
afueras de la ciudad de Santiago, la capital del Reino.-

"Por nueve meses violentamente se les ha impuesto por la administración de la

pólvora, la nueva pena de contribuir semanariamente, ya con 10 ya con 12 y aún con 14 indias viudas, sin habérseles hecho saber hasta ahora, la orden superior a cuya virtud procede dicha Administración.”3

Aunque no lo desean, se ven compelidas por las autoridades, que sin ninguna explicación les han ordenando que cumplan las órdenes. Su situación es muy precaria, ya que son indias cackchiqueles, del pueblo de Jocotenango y llevan una pesada carga.

Descendientes de los pueblos conquistados, viven en un lugar, que los españoles ven como una prolongación de la ciudad de Santiago, pueblo del cual se saca gente para el trabajo. Tradicionalmente emplean a los hombres para la albañilería, y algunos artesanos se dedican a la fabricación de "avíos para las cabalgaduras de silla y carga" son además de proveedores, un ejército de reserva de mano de obra. Las mujeres son reconocidas como molenderas

Los terremotos de Sta. Marta del 29 de julio de 1773 sacudieron el valle por más de un mes, causan la destrucción de la ciudad de Santiago a tal punto que se decide el traslado de la misma al Valle de las Vacas.

La fábrica de pólvora, que suplía las necesidades militares del Reino, también había sufrido y el molino de pólvora se descompuso; por lo que se dieron "las provisiones más activas para que por medio de indias molenderas se fabrique la pólvora que sea posible" . "La falta de pólvora en el Reyno y la necesidad de defenderlos (. . .) el interés que tiene la Religión y el estado en resistir sus verdaderos enemigos obligaron a dictar la providencia de que se fabricase la pólvora que fuese posible por medio de indias molenderas. Esta indispensable, prudente y sabia resolución es puramente provisional y tomada mientras se compone el molino 
que tiene el Rey en la Antigua Guatemala". ${ }^{\circ}$

Sin embargo, esta situación de emergencia, se alargó sin ninguna explicación, parece ser que la persona encargada de la reconstrucción de dicho molino no hizo nada para reconstruirlo7 . Las mujeres, están cansadas de prestar un servicio, que además de ser forzado, está mal pagado y les daña su salud. Acuden al cura del pueblo para que las ayude. Este párroco asume la defensa de sus feligresas y en el proceso genera documentación que es la base de ésta investigación.

Las repetidas protestas caen en oídos sordos. Finalmente en 1798, por medio de un edicto, se ordena que se traslade la elaboración de pólvora a la nueva fábrica que se ha edificado en la antigua Guatemala, y que se suspendan "las labores de pólvora que la necesidad obligó a emprender por medio de molenderas"

Antes de entrar al análisis de la documentación sobre el trabajo de las mujeres de Jocotenango se hace necesario tomar en consideración la trama que subyace en el tejido de esta historia.

\section{La problemática del trabajo femenino}

El análisis de la documentación arroja información muy variada que amenaza con desviarnos del objeto de este estudio: rescatar un retazo de la historia de las mujeres en Guatemala y develar su contribución mujeres a la economía del Reino a través del trabajo forzado en la molienda de los mixtos para producir pólvora.

Hay que considerar que el trabajo fue reconocido tardíamente, después de la Revolución Francesa (1789), como un derecho. Por lo tanto en la época que nos ocupa el trabajo era una obligación impuesta por las necesidades del Estado y la Iglesia y las que exige 
la supervivencia, no era fuente de prestigio para los hombres, por lo que a lo que las mujeres se refiere siempre ha ido a la saga.

Hasta la actualidad, mucho del trabajo de las mujeres no se considera trabajo sino una extensión de su naturaleza femenina, porque "la mujer está definida por sus funciones y sus funciones sociales se definen como naturales"9 Por lo tanto la relación de las mujeres con su trabajo, no es igual a la de los hombres.

En este caso particular el servicio personal es sólo una extensión de lo que es natural, según un funcionario real: "las mujeres de Jocotenango, son molenderas"10. Aquí pesa también que el pueblo fue fundado para garantizar el sustento y supervivencia de Santiago, los de Jocotenango para eso están y las mujeres son molenderas, no se les está sacando de lo que ya están acostumbradas.

Pero en la realidad, y en esa época la familia era también una unidad económica. En el hogar se hilaba, tejía y cultivaba, se cuidaban gallinas y los excedentes se intercambiaban ya en la plaza ya en transacciones personales. La alarma del cura está motivada también porque se ha roto el orden natural de las cosas. Al final del día si disminuía aún más el número de sus feligreses, su propio sustento estaba en peligro. (

\section{El pueblo:}

Después de su asentamiento en la ciudad de Santiago, los españoles se ocuparon de asegurar el abasto de todo lo que la ciudad necesitaba para su supervivencia. Empezaron a fundar pueblos no más lejos de tres leguas de la ciudad. Según Domingo Juarros "De estos pueblos se seguía gran utilidad a sus vecinos, pues en ellos hallaban copia de manos que emplear en sus labores, y abundancia de víveres y otras cosas necesarias para la vida o para 
el regalo"11. Jocotenango fue fundado por Pedro de Alvarado quien pidió a los señores principales que tenía en encomienda que le dieran familias de sus parcialidades y con ellas fundó el pueblo. A la altura de nuestro relato, el pueblo contaba con aproximadamente 3,735 almas.

Sabemos las circunstancias de su fundación, pero falta considerar el aspecto sociocultural. Según el obispo Cortés y Larras, el pueblo presenta características diferentes a los indios mejicanos Tlascaltecas quienes, a dos siglos y décadas de la conquista, dominaban el castellano y habían olvidado el Nahuatl. No así los cackchiqueles de Jocotenango que habían conservado su idioma tradicional y se negaban a bautizarse y asistir a la escuela El obispo así lo expresa: "se retardaba a los niños el sacramento del bautismo , en algunos hasta un año, y aún haberle sucedido llevarle a bautizar uno de cinco años, que fue por su propio pie (...) y todo a pesar de los fiscales y mayordomos de las cofradías observaran en qué mujeres se veían indicios de estar próximas al parto"12. En la actualidad está claro que este grupo presentaba resistencia a la integración en la cultura ladina, y las instituciones como Escuela e Iglesia, eran una clara amenaza para la permanencia de su cultura. Posiblemente su renuencia era acentuada por la constante amenaza que representaba la cercanía de la ciudad de Santiago que los colocaba en dependencia directa hacia ella. Sin embargo, la conclusión del obispo fue adjudicar este hecho sorprendente al interés de los párrocos regulares por conservar la lengua de los indígenas: "hay tanto y tan variados idiomas maternos, ni saben ni hay esperanzas de que lleguen a saber el castellano (. . .) Por lo que entiendo que la principal razón de esta diferencia puede consistir en ser los otros idiomas más bárbaros que el mexicano, y con ellos trascender la barbarie a los sujetos"13 En pocas palabras: eran vistos con desdén. 


\section{La parroquia:}

Era parte de la Arquidiócesis de Guatemala y según la norma decretada por el Tercer Concilio Mexicano (1585) «los curas deben residir en la casa parroquial para poder administrar mejor los sacramentos.» (. . .) debían decir misa todos los días, formar padrones en los pueblos de indios y enseñarles el catecismo. ${ }^{14}$ La importancia de la parroquia dependía del número de feligreses, y la cantidad de los agregados, ya que los poblados o iglesias dependientes aumentaban la población del curato y por ende los ingresos del cura. La parroquia de Jocotenango no tenía anexos ${ }^{15}$

\section{El estatus de las mujeres:}

Mucho se puede abundar en este tema, pero por razones de espacio solo aclaro lo esencial para la comprensión de este trabajo. En la sociedad patriarcal las mujeres están relegadas a un segundo plano, sus logros y contribuciones se incluyen como parte no nombrada de la sociedad, por lo tanto se olvidan se "invisibilizan", son entrenadas a vivir para otros.

El encargado de designar a las mujeres que tenían que prestar el servicio, era el gobernador indígena que normalmente pertenecía a la parcialidad de los Guatimaltecas ${ }^{16}$, y escoge, no por casualidad, viudas. Las viudas indígenas estaban totalmente desprotegidas ante el Estado y la comunidad. Eran el grupo más vulnerable de las sociedad colonial ya que eran libres y no estaban protegidas por el reglamento de educación de esclavos que contenía prescripciones claras respecto a la manutención, cuidado de la salud, y horario de trabajo; por lo tanto podían ser fácilmente abusadas ${ }^{17}$. Buscan protegerse "bajo la sombra de un hombre"18 en este caso el cura párroco, que además era español. 


\section{Análisis de los documentos:}

Este documento está lleno de elementos que habitaban y aún permanecen en el imaginario colectivo ${ }^{19}$, aunque los hechos lo contradigan. Por ejemplo: los indígenas sufren en silencio.“Que he advertido padecer por este mi pueblo, por las clamorosas quejas que me dan sus individuos, en medio de aquel silencio con que sufren y callan en las demás pensiones y servidumbres y cargas que han soportado siempre y soportan hasta el día a pesar y en perjuicio muy notable de sus comodidades, de sus intereses y aún de su conservación y vida."20

En la documentación producida, se establece un diálogo de sordos entre el cura párroco y las autoridades reales. El enfrentamiento con el Estado está latente ya que no desafía la autoridad sino que denuncia que no se les ha informado a las mujeres quién es el responsable (de su desgracia $)^{21}$. El presbítero Pineda subraya la vulnerabilidad de las viudas cuando razona que:"Si para el añil y la nieve ${ }^{22}$, el Rey tiene piedad y se ejercitan "voluntarios” a estas actividades, (. . .) "con mayoridad de razón debe presumirse no ser de su real voluntad que con apremio se dediquen las indias, a los penosos y mas dañosos ${ }^{23}$ beneficio de la pólvora, de cuyas resultas he visto ya indias adolecer gravemente de los ojos y de recia y continua tos y mas de otras que me aseguran también haber enfermado" 24 .

A pesar de los repetidos reglamentos para el trabajo forzado de los indios, Landecho y otros, las regulaciones fueron ampliamente ignoradas. Los vecinos y autoridades españolas abusaban de los indios con impunidad, no se respetaba la alternabilidad ni el hecho de que las mujeres fueran viudas. Para agravar la injuria que ya reciben las viudas, existen otros agravantes:

1-El jornal: 8 reales por semana, está por debajo de los acostumbrado. “A la fábrica se le proporcionaban todos los indios necesarios para su operación, que recibían un salario de dos 
reales diarios”25. Es decir que a las mujeres les pagaban la mitad que a los hombres por un día de trabajo.El presbítero argumenta que con un real diario no se pueden mantener a sí mismas, menos a su familia "haviendo quien cuente de ella hasta 5 hijos, todos pequeños, que dejan abandonados" (. . .) En otro trabajo, ya sea en su propio pueblo o en las cercanía de la ciudad: “en las casas de la ciudad contigua a él, en subsidio de sus indigencias y sin perjuicio de la asistencia y cuidado, tan necesario de sus criaturas, de sus pobres casas y haveres sic y sin detrimento también de su salud"26 Aquí subyace la oposición a que estén sacando a la mujer de su hogar, que es su lugar, aunque es obvia la necesidad de sustentar su existencia, ya que no reciben pensión del estado. Por lo tanto es una pena que se les envíe a un lugar que las enferma porque eso pone en peligro a toda la unidad familiar y sobrecarga a la sociedad con los ya numerosos huérfanos y huérfanas.

2- La ración alimenticia es insuficiente: "sin más alimento que una escasa ración al mediodía, que tiene valor de un cuartillo ${ }^{27}$. "por lo que es necesario se ocupe otra (mujer) de la administración de la casa de cada india, para llevarle desde tan lejos a la hora en que pueden adquirirlo" Aquí se refiere a los daños a terceros, ya que la penuria de una interrumpe el transcurso de la vida cotidiana de otra, por lo que se hace una cadena que al final hiere a todo el pueblo. Por otra parte, aquellos trabajadores que ganaban muy poco debían recibir una ración que a veces era una libra de carne, diaria, por persona, porque interesaba que estuvieran vigorosos para rendir en el trabajo. En este caso, dicha preocupación no existía, porque desde un principio este trabajo se consideraba como temporal. Sin embargo, el Administrador argumenta que: Reciben "una comida que aunque no es ventajosa es siempre mejor que la que tienen en su pueblo" 28 
3- La tarea es excesiva: Por si fuera poco el jornal no corresponde al gran trabajo "que le es necesario emprender, para dar cumplimiento a las excesivas tareas que diariamente se les impone”. La respuesta del la administración de la pólvora minimiza la afirmación diciendo que la tarea es la molienda de 5 libras de mixtos por lo que se les paga dos reales y que las que son más eficientes podían hacer un peso a la semana ${ }^{29}$

4-El exceso de horas que les roba el trabajo: Se tienen que juntar desde muy de madrugada en la plaza del pueblo para ir a la fábrica. Prosigue: "por un real al día y parte de la noche, ya que empiezan a trabajar a las 6:00 AM. y retornan al pueblo a las 7:00 p.m. En este sentido a los esclavos y esclavas negras les iba mejor ya que las labores terminaban al caer el sol sin tener la molesta de regresar a su pueblo ya que ellas vivían en el trabajo. El administrador responde que salen a las 6 p.m. "al menos que alguna quiera empeñarse en terminar su tarea"30. Obviamente, si no terminaban su tarea, no les pagaban el día, entonces tenían que "empeñarse" hasta terminarla.

\section{5- Los prejuicios en contra de los oprimidos:}

-Administrador: "Se dice que en su pueblo podrían ganar mucho más con menos trabajo, ¿en qué ocupación o ejercicio lograrían tanta fortuna unas indias naturalmente ociosas y propensas a la embriaguez?" Aquí se introduce el argumento de la naturaleza corrupta que se le adscribe a los grupos subyugados. Hace caso omiso de los argumentos del cura que son comprobados y documentados:

-Padre Pineda "la grave vejación que padecen las indias en el servicio personal que prestan a solicitud de la Administración de la pólvora, para moler los ingredientes de ésta composición, 
con daño a su salud y familias. Sin la debida alternación y sin competente jornal, ni alimentos" Ante la insistencia del presbítero le habían pasado el asunto al Oidor fiscal pero no hace nada al respecto, Pineda exige: “ que el administrador de la pólvora evacues sin más dilación el informe que se le ha mandado hacer sobre este particular” ${ }^{31}$ aquí se apunta la fecha 20 de dic. 1797 - Administrador: El Padre cura de Jocotenango "no conoce todavía que la verdadera felicidad de las indias consiste en evitarles la ociosidad, a que son sumamente propensas. (. . .) En antigua se emplean más de 50 molenderas "Concurriendo muy contentas al trabajo"32 Además "han sorprendido la buena fe del padre cura Don Manuel de Pineda induciéndole a que tome a su cargo este asunto y que abulte y exagere hasta las nubes"33. "Las enfermedades que se atribuyen es un fantasma muy gracioso ¡Ardor de ojos! ¿De donde se puede deducir con verdad cristiana que la molienda de los mixtos para la pólvora originó aquella enfermedad?"34 En resumen deja asentado que las mujeres exageran y mienten.

\section{6- El Párroco:Ya son muchos los servicios que prestan a la ciudad Capital:}

Las parcialidades de Jocotenango estaban obligadas a enviar tres veces por semana: treinta indios para limpiar el palacio de la Audiencia, cuarenta y seis yerbateros a la semana, quienes recibían dos o tres reales a la semana por este trabajo. Tres chichiguas a la semana y seis hombres para limpiar las letrinas de la cárcel de la ciudad, sin recibir pago alguno. Esto sin contar los enormes proyectos de construcción: acueductos, carreteras, y edificios públicos, más el servicio ordinario que incluía el aprovisionamiento de agua, leña, y servicio para las casas de los españoles. ${ }^{35}$

7. La doble carga que llevan las viudas: Si bien los hombres cumplen la mayoría de los trabajos forzados, este hecho transfiere la carga de la producción a las mujeres, que viven tan 
atareadas de por sí. El cura reconoce la doble carga que las mujeres llevan cuando se tienen que ganar la tortilla y cuidar de sus casas. Especialmente las viudas que padecen la ausencia permanente del marido:

"Las mujeres apenas pueden dar alguna asistencia a sus familias y demás cuidados domésticos, exige la equidad que entre tanto se determina el expediente sobre los servicios personales de los indios varones, al menos las hembras no sean gravadas igualmente que aquellos, en servicio de esa república" ${ }^{36}$ sino que se adjudique a ellas, cuando no a algunas de tantas ladinas que no faltan en la ciudad, sin destino, y que sería de algún beneficio de ellas en lo espiritual y corporal ocuparlas". Alude a la vida licenciosa que llevan las mujeres de las castas, otro prejuicio de la época y parece también dejar de lado el daño a la salud que provoca la dicha actividad. Las mujeres de las castas eran sobrevivientes: Sin la protección-opresión de los nexos que proveían las comunidades indígenas a sus miembros, tenían que encontrar la forma de "salir adelante" a través de los mecanismos de explotación sexual, comercio clandestino, producción de bebidas embriagantes y todo lo que estuviera a su alcance, legal, moral o no.

\section{8- La falta de alternatividad:}

Hay indios de otros pueblos que no tienen tantas cargas como los de Jocotenango, podrían utilizarse "ya estos indios han soportado por el largo espacio de tantos meses, según queda dicho, estas duras, penosos y nocivas servidumbres, en que no puede ser, conformes que continúen ellas mismas y más cuando no permiten los dependientes de la referida administración ; ni aún que se turnen entre sí las viudas todas" Sino que las que ya pueden , se ocupen " en contra del espíritu de las leyes, sin intervención ni descanso" de la fabricación de 
pólvora. Es el caso de "Unas llevan ya 5 meses de ir todos los días pide "que se les imponga a las de los otros pueblos" que se partan la carga "alternativamente y con igualdad" "a V.S. suplico sea muy servido mandar a la administración de pólvora no concurra en lo sucesivo a este pueblo por repartimiento de Indias" ${ }^{\$ 7}$. Hay que hacer notar que el repartimiento en letra era una cosa, y en la práctica era otra. De manera que los indios que tenían buenas relaciones con el gobernador o podía pagarle a otro para que lo substituyera se libraba del repartimiento. De manera que los más débiles social y económicamente cargaban con el peso de todos. En este caso las viudas eran las más vulnerables porque ni tenían un esposo que reclamara por ellas, no tenían voz, tenían que buscar, como ya hemos dicho la "sombra de un hombre" para que su malestar se hiciera oír.

A continuación se suceden los argumentos de Francisco Arze, funcionario real. Argumentos sorprendentemente actuales de funcionarios no de la corona, pero sí de la república.

\section{9- Administrador: Cuando la supervivencia del reino está en juego todos deben}

sacrificarse.Como se le había pedido que informara cuantas indias llegaban de Jocotenango, al administrador admite que: "al principio 5 y de octubre a la fecha, diciembre, son 13, por la urgencia de la presente guerra" . Argumenta que el Reino está en una cruenta guerra, sin embargo no dice contra quién ni por qué. Lo único que me fue posible constatar en esas fechas es que en 1796 los ingleses ocupan las islas de la bahía, frente a las costas de Honduras. E introducen caribes negros en la isla de San Vicente y un año después la se logra la expulsión de los ingleses de dichas islas y la deportación de los negros garìfunas de la isla de san Vicente, a Roatàn. ${ }^{38}$ Prosigue su argumentación y para endulzar el oído del que recibe la misiva "otros se sacrifican por la felicidad de estos Reynos incluyendo al hijo de V:S, al paso que casi acusa 
al Padre de traición cuando señala: “ sería creíble que estando dispuestos todos los habitantes de este Reyno dispuestos defenderlo con sus vidas (. . .) sólo el cura de Jocotenango haya tenido la desgracia de dar un paso tan distante de su notorio celo y cristiandad" En pocas palabras subraya el hecho de que el cura no tiene por que meterse en cosas que conciernen al Estado. La enfermedad de ojos de una india y la tos de otras pocas no son nada cuando la patria está en peligro.

\section{0- Administrador:Es una fuente de trabajo}

_Qué diría el cura si supiera que "Lejos de haber experimentado daño han sido sumamente beneficiadas de la molienda de la pólvora. Nadie ignora la epidemia de tabardillo y de sarna que sufre Jocotenango y como el azufre es el verdadero remedio para este mal, es muy de creer que la salud que han logrado las molenderas de pólvora ha promovido de este principio, pues no se señala que haya muerto siquiera una de las que han ido a trabajar a la administración ${ }^{39}$ Después de 1 año de estar en la lucha , el administrador suspendió desde el 24 de diciembre de 1798 esta práctica porque ya se compuso el molino. Y no existe causa para seguir el expediente, 12 de febrero de 1800.En ese mismo año, termina la reconstrucción de la fábrica y el nuevo encargado de la supervisión de la obra ,del 22 de febrero de 1798 al 31 de diciembre de 1899, Don Ignacio Palomo, recibe 600 pesos.

\section{Reflexiones finales:}

Siguiendo el símil de sociedad como un tejido podemos observar que:

Oficialmente Iglesia y Corona tenían las mismas metas en la construcción de América, sin embargo siempre hubo un pulso de fuerza que intentaba torcer el brazo del otro. En esta 
época el conflicto se había acentuado debido al traslado de la Ciudad de Santiago al Valle de la Ermita. La iglesia se oponía a ello y hacía todo lo posible por resaltar los "daños y penas" que sufrían los indígenas, sin mencionar las pérdidas y daños que sufría la institución como tal. El traslado forzoso del pueblo de Jocotenango, que era visto como una prolongación de Santiago tiene mucho peso en esta época aunque no se menciona ni una sola vez en la documentación manejada. Se decretó el traslado pero no se trasladó el pueblo entero. Por lo tanto las viudas fueron dejadas atrás porque como molenderas no eran indispensables en la construcción de la Nueva Guatemala de la Asunción.

La postura pragmática de parte de los funcionarios reales que veían a la población americana como objetos para la construcción del imperio español en América, su provecho y bien estar, se enfrenta a la actitud lascasiana de proteger a los débiles y engrandecer el nombre de Dios, sin mencionar los beneficios económicos que los curas párrocos y ordenes religiosas extraían de estas "almas".

Aunque al inicio de la colonización las órdenes religiosas eran mendicantes, luego se convierten en verdaderas empresas productivas y comerciales, los convertidos pronto tienen que pagar con trabajo, diezmos y ofrendas a la "casa de dios".

La protesta del presbítero Pineda es una respuesta a los excesos cometidos por la Corona que amenazaban dejarlo sin feligreses. En este caso particular, el párroco, ya había salido a la defensa de las mujeres chichiguas, caso que ya fue estudiado por la historiadora Rosa María Álvarez y el historiador Stephen Webre.

La respuesta de los funcionarios reales, nunca enfrentan el problema de la explotación excesiva, sino que tratan de desacreditar al cura, insinuando que no sabe cómo son las cosas. Por un lado que se deja engañar, por las mujeres, que son mentirosas exageradas, haraganas 
y ebrias, (de allí el título de esta ponencia) y por otro, que se desvía del camino correcto al anteponer los intereses de la Corona y de La Iglesia, a los de las indias.

La situación de desamparo de las viudas en la época estudiada se vuelve a reafirmar en el hecho que eran no sólo mujeres indígenas sino que todas ellas viudas las que fueron escogidas por el gobernador indígena para ejecutar trabajo forzado en la fabricación de pólvora. Por esta misma razón los argumentos de los funcionarios reales van encaminados a la actitud tan presente esta hoy: deberían de estar agradecidas de que se les da la oportunidad de ser útiles a la sociedad y ganar un salario fijo.

El trabajo de las mujeres en la fabricación de pólvora contribuyo a erario del Reino 13,50040 pesos anuales, como consta en las cuentas de los Libros Reales de diarios. En las cuentas del estanco de la pólvora y los naipes ${ }^{40}$. Y según Francisco Arze, encargado del molino la venta de pólvora, en el período de este conflicto con el padre Pineda fue de 4,709, 53pesos. Cifra nada despreciable.

Sin embargo, aunque de ellas dependía la fabricación de la pólvora, que a su vez era indispensable "para la supervivencia y felicidad de estos reinos", se les pagaba la mitad que a los hombres, sin que medie explicación alguna. Simplemente en una sociedad patriarcal el trabajo de las mujeres, no es trabajo, por lo tanto no hay que pagarles tanto como a los hombres.

Como antes sucedió con Bartolomé de las Casas, que para proteger a los indios, pidió se importaran esclavos negros, el Padre Pineda pide "que le impongan esta carga a las muchas ladinas que vagan ociosas por la ciudad o a las indias de los más numerosos pueblo circunvecinos que no han llevado esas cargas ni otras que sí llevan las de Jocotenango, 16 de abril 1798" Parece pasar por alto que si sus peticiones fueran escuchadas, la carga y la 
Indexaciones: Repositorio de Revistas UCR, DIALNET, Latindex, REDALYC Directorio y recolector de recursos digitales del Ministerio de Cultura de España, Directory of Open Access Journals. Diálogos Revista Electrónica de Historia ISSN 1409- 469X. Número especial 2008. Dirección web: http://historia.fcs.ucr.ac.cr/dialogos.htm

enfermedad pasarían a otros. Bajo las circunstancias esto no parece interesarle. Le importaban sus feligresas.

\section{(Endnotes)}

1 Evellyne Sullerot, Sociología del trabajo femenino, 1988:11

2 Publicado en Anales LXXVII, pp.123-162;2002

3 AGCA. Sig. A.3. Leg.216, Exp. 3881. Fol.1 Año 1800

4 Zilbermann de Luján, Cristina: Aspectos socioeconómicos del traslado de la ciudad de Guatemala (1773-1783). Guatemala: Academia de Geografía e historia de Guatemala, 1987. p.

5 Sig. A·. Leg.216. Exp. 2968. año 1798

$6 \quad{ }^{6}$ AGCA. Sig. A.3. Leg.216, Exp. 3881. Fol.6 Año 1800

7 Sig. A1. Leg.216. Exp. 2968. año 1798

$8 \quad 8$ AGCA. Sig. A3. Leg.216, Exp.3873. Año1799

9 Sullerot, 1988:11

10 Sig. A·. Leg.216. Exp. 2968. año 1798,fol 8

$11{ }^{11}$ citado en Sanchiz Ochoa, Pilar : Los Hidalgos de Guatemala 1989. p. 36

12 Pedro Cortés y Larráz: Descripción Geográfica y Moral de la diócesis de Goathemala. T.I, Guatemala: C. A. Biblioteca “Goathemala” de la sociedad de Geografía e Historia vol.XX, 1958. p41.

13 Op. Cit. P.41 
Indexaciones: Repositorio de Revistas UCR, DIALNET, Latindex, REDALYC Directorio y recolector de recursos digitales del Ministerio de Cultura de España, Directory of Open Access Journals.

Diálogos Revista Electrónica de Historia ISSN 1409-469X. Número especial 2008. Dirección web: http://historia.fcs.ucr.ac.cr/dialogos.htm

tuvieron vigencia para la Iglesia americana hasta el Concilio Vaticano II en la década de los sesenta del siglo XX.

La Iglesia Católica no ordenó ningún cambio en asuntos parroquiales desde 1585 hasta el siglo XX. Ver Johan

Melchor Vida social y religiosa de la Antigua Guatemala

y los pueblos vecinos de 1780 a 1820, Guatemala, UVG,2003p.8

15 Cortés y Larráz, op cit.p.40

16 El pueblo de Jocotenango estaba constituído por varias parcialidades, los guatimaltecas, los utaltecas y los sacatecas. No encontré evidencia que las viudas designadas pertenecieran a una parcialidad en particular. Por la indiferencia al sufrimiento y daño a la salud de estas mujeres, se presenta la duda si eran de una "minoría", sin embargo no poseo información suficiente al respecto. Lo planteo como una pregunta para futuras investigaciones.

17 Ver: Beatriz Palomo de Lewin "Esclavos negros en Guatemala" tesis de licenciatura, Guatemala: UVG, 1991

18 Esta frase se encuentra en aquellos documentos que pretenden nombrar a un hombre como protector de una o varias mujeres. moler en piedras de mano , el azufre y demás mixtos que expresa

20 Sin embargo los indígenas, desde muy temprano aprendieron a transmitir sus reclamaciones a la autoridad, para mayor información ver: Dakin, Karen y Christopher Lutz : Nuestro pesar ,nuestra aflicción,

UNAM,CIRMA, 1996, pp. 77-81

21 La responsabilidad de señalar a quién va es del gobernador de Jocotenango AGCA. SA.3. L.216, E. 3881. Año 1800,fol. 6.

22 Tanto el obraje de añil como la fabricación de "la nieve" ponía en peligro la salud de los indios. Por lo tanto 
por medio de un auto del 15 de mayo de 1590, la Audiencia prohibió el uso de indígenas para el obraje de añil, pero se siguieron usando indios "voluntarios" para ambas actividades. Para 1738, cuando la población indígena se había recuperado, se derogó la prohibición por medio de Real Cédula. Sin embargo se reconocía que dichas actividades eran peligrosas. Ver: Beatriz Palomo de Lewin: Esclavos negros en Guatemala (17231773) Trabajo de Graduación, Universidad del Valle de Guatemala, 1992. Cap VI.

23 AGCA. SA.3. L.216, E. 3881. Año 1800, fol. 6

24 AGCA. SA.3. L.216, E. 3881. Año 1800,fol 2.

25 Johnston: op.cit, p. 13

26 op. Cit. fol.3

27 AGCA. SA.3. L.216, E. 3881. Año 1800, fol. 6

28 AGCA. SA.3. L.216, E. 3881. Año 1800, fol. 6

29 AGCA. SA.3. L.216, E. 3881. Año 1800, fol. 4

30 AGCA. SA.3. L.216, E. 3881. Año 1800, fol. 6

31 Ibid. fol. 6

$32 \mathrm{El}$ argumento se dirige a probar que las ladinas, llegan muy contentas a trabajar, pero las indígenas, que como tudo el mundo sabe, son holgazanas, van y se quejan con el cura-

33 AGCA. SA.3. L.216, E. 3881. Año 1800, fol. 7

34 Op. Cìt. Fol. 8 Lo escalofriante de este argumento es que no dista mucho del usado por las corporaciones mineras hoy en día cuando hay protestas relacionadas con las dolencias que sufren los pueblos que consumen el agua cercana a las minas.

35 Lutz, Christopher H.: Santiago de Guatemala, 1541-1773: city, caste, and the colonial experience. U.S.A, University of Oklahoma Press,1994, pp.22-23 


\section{9 $9^{\circ}$ CONGRESO \\ - 8 CENTROAMERICANO \\ DE HISTORIA \\ Universidad de costa Rica}

Indexaciones: Repositorio de Revistas UCR, DIALNET, Latindex, REDALYC Directorio y recolector de recursos digitales del Ministerio de Cultura de España, Directory of Open Access Journals. Diálogos Revista Electrónica de Historia ISSN 1409-469X. Número especial 2008. Dirección web: http://historia.fcs.ucr.ac.cr/dialogos.htm

36 AGCA. SA.3. L.216, E. 3881. Año 1800, fol. 3r

37 op. Cit. Fol. 4

38 Jorge Lujàn : HGG, Tomo III. p. 694

39 AGCA. SA.3. L.216, E. 3881. Año 1800, fol. 8

AGCA. Sig. A3, Leg.213, Exp.3792, año:1778 
Indexaciones: Repositorio de Revistas UCR, DIALNET, Latindex, REDALYC Directorio y recolector de recursos digitales del Ministerio de Cultura de España, Directory of Open Access Journals.

Diálogos Revista Electrónica de Historia ISSN 1409-469X. Número especial 2008. Dirección web: http://historia.fcs.ucr.ac.cr/dialogos.htm

\section{Bibliografía}

Cortés y Larráz, Pedro: Descripción Geográfica y Moral de la diócesis de Goathemala. T.I,

Guatemala: C. A. Biblioteca "Goathemala” de la sociedad de Geografía e Historia vol. XX, 1958. p41.

Dakin, Karen y Christopher Lutz : Nuestro pesar, nuestra aflicción, UNAM,CIRMA, 1996

Johnston, René: De Santiago de Guatemala a la Villa de la Antigua Guatemala transformación y vida social ante una crisis .Trabajo de graduación, Universidad del Valle Guatemala, 1997 "La real fábrica de Pólvora en Santiago de Guatemala " en Anales LXXVII

Lutz, Christopher H.: Santiago de Guatemala, 1541-1773: city, caste, and the colonial experience. U.S.A, University of Oklahoma Press,1994,

Melchor Toledo, Johann Estuardo: Vida social y religiosa de la Antigua Guatemala y los pueblos vecinos de 1780 a 1820. Trabajo de graduación . Guatemala: Universidad del Valle de guatemala, 2003

Palomo de Lewin, Beatriz: “Esclavos negros en Guatemala, 1723-1773” tesis de licenciatura, Guatemala: UVG, 1991

Sanchiz Ochoa, Pilar : Los Hidalgos de Guatemala,1989. 
Indexaciones: Repositorio de Revistas UCR, DIALNET, Latindex, REDALYC Directorio y recolector de recursos digitales del Ministerio de Cultura de España, Directory of Open Access Journals.

Diálogos Revista Electrónica de Historia ISSN 1409-469X. Número especial 2008. Dirección web: http://historia.fcs.ucr.ac.cr/dialogos.htm

Sullerot, Evelyne: Historia y sociología del trabajo femenino, Barcelona: Ediciones Península, 1988

Zilbermann de Luján, Cristina: Aspectos socioeconómicos del traslado de la ciudad de

Guatemala (1773-1783). Guatemala: Academia de Geografía e historia de Guatemala, 1987

40

\section{Documentos del archivo General de Centroamérica:}

AGCA. Sa.3. L.213,E3792. Año 1778 Administración de la fábrica de pólvora. Mariano Rodríguez de Rivas, pide en 1777 que se le nombre un ayudante, ya que no puede rendir cuentas como lo pide la real hacienda por falta de tiempo.

AGCA. SA.3. L.216, E. 3881. Año 1800 El presbítero Manuel Pineda, cura párroco de Jocotenango denuncia que : la administración del ramo, hace que semanalmente acudan 14 indias, viudas de Jocotenango a moler en piedras de mano , el azufre y demás mixtos que expresa

AGCA. Sig. A.3. Leg.216, Exp. 3881. Fol.6 Año 1800 Donde se explica el por qué de la disputada orden. 